\title{
Is Depression an Adaptation?
}

Randolph M. Nesse, MD

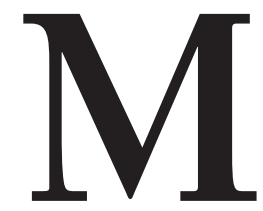

any functions have been suggested for low mood or depression, including communicating a need for help, signaling yielding in a hierarchy conflict, fostering disengagement from commitments to unreachable goals, and regulating patterns of investment. A more comprehensive evolutionary explanation may emerge from attempts to identify how the characteristics of low mood increase an organism's ability to cope with the adaptive challenges characteristic of unpropitious situations in which effort to pursue a major goal will likely result in danger, loss, bodily damage, or wasted effort. In such situations, pessimism and lack of motivation may give a fitness advantage by inhibiting certain actions, especially futile or dangerous challenges to dominant figures, actions in the absence of a crucial resource or a viable plan, efforts that would damage the body, and actions that would disrupt a currently unsatisfactory major life enterprise when it might recover or the alternative is likely to be even worse. These hypotheses are consistent with considerable evidence and suggest specific tests.

Arch Gen Psychiatry. 2000;57:14-20

Pain or suffering of any kind, if long continued, causes depression and lessens the power of action; yet it is well adapted to make a creature guard itself against any great or sudden evil.

The Life and Letters of Charles Darwin, Charles Darwin, 1887

Some manifestations of disease arise directly from a defect in the body's machinery while others are defenses or dysregulations of defenses. ${ }^{1,2}$ Manifestations of disease that arise directly from defects, such as jaundice or seizures, have no utility. However, defenses such as pain or diarrhea are adaptations shaped by natural selection. Dysregulated or extreme defenses cause many diseases, such as chronic pain or dehydration from diarrhea. Distinguishing manifestations of disease that arise from these 3 causes is important. Correcting a defect is almost always useful, but blocking a defense can be harmful. For instance, drug treatment of Shigella-induced diarrhea often causes complications. ${ }^{3}$ Searching for the cause of a defect starts with the defect itself, but the cause of a defense, such as cough, is sought in the abnormality that arouses it, not in its mediating mechanisms.

Is depression an adaptation, an adaptation gone awry, or a pathological state unrelated to any function? Opinions range from dismissal of the possibility that depression or low mood could be useful to the conviction that even severe depression is an adaptation with a specific function. ${ }^{4}$ These opinions have important practical consequences. Patients who believe that depression is normal may refuse drug treatment for fear of "covering up the real problem," while those who believe depression is purely a product of brain pathology may be reluctant to examine how their relationships may contribute to their symptoms. Clinicians who believe depression is an adaptation may spend years trying to help a patient understand its significance, while other clinicians actively discourage such inquiry. The physiological changes associated with depression are assumed to be defects by many researchers, while others see them as merely reflecting the activity of mood regulation mechanisms. Despite huge advances in our ability to treat depression and growing rec- 
ognition that it is often a medical disease resulting from multiple pathways, ${ }^{5}$ fundamental disagreements continue about its adaptive significance.

Terminology is inconsistent in this area. Those who see depression as intrinsically pathological tend to reserve the word for severe states that are mostly unrelated to ordinary mood variation, while those who see it as a defense use the same word to cover a wide range of normal and abnormal states. In this article, depression will refer to severe states of negative affect that are often but not necessarily pathological, and low mood will refer to states in the common range of normal experience. Low mood and depression have been difficult to distinguish from each other and from related states such as sadness, grief, demoralization, guilt, and boredom. This difficulty may reflect the nature of the organism. Natural selection may have gradually and partially differentiated a generic state of inhibition into subtypes specialized to cope with particular kinds of situations. Sadness, depression, guilt, and grief may be partially differentiated members of a "fuzzy set"6,7 whose commonalities are explained partially by phylogeny and partially by the benefits certain responses offer in any unpropitious situation.

Many people believe that low mood is normal and probably useful in certain situations, but when excessive, prolonged, or expressed in the wrong situation, it becomes pathological depression. This plausible starting position gives rise to several questions: In what situations is low mood useful? How does it give a selective advantage? At what level of severity does low mood become pathological depression? Is some depression unrelated to low mood? Firm answers to these questions will not be possible until we better understand the evolutionary origins and functions of low mood. These questions about why the capacity for mood exists at all are separate and distinct from proximate questions about the psychological and brain mechanisms that cause low mood, and from the question of why people differ in their vulnerability to low mood or depression.

\section{GLOBAL EVIDENCE}

The match between the eye's complex form and its function demonstrates that it is an adaptation, while seizures are obviously a defect. Do the global characteristics of low mood or depression give clues to their adaptive significance? Depression is painful and interferes with normal function, so it seems obviously maladaptive. However, other useful capacities, such as pain, nausea, and fatigue, are also aversive and disruptive. In fact, their very aversiveness is likely a product of natural selection, probably because they promote escape and avoidance of situations that decrease fitness. From this perspective, the intrinsic aversiveness of most low mood and depression suggests that they may be related to a defense.

The epidemiology of mood disorders offers other clues. If depression were rare, like schizophrenia, and had symptoms unrelated to the experiences of most people, this would suggest it was a disease unrelated to any defense. In fact, major depressive disorder affects about $10 \%$ of the US population in a year. ${ }^{8}$ Depressive syndromes that do not meet diagnostic criteria are even more common. ${ }^{9,10}$ Furthermore, there is no point of rarity in the distribution that can differentiate pathologic from nonpathologic depression, ${ }^{11}$ and subjects move frequently between syndromal and subthreshold depression over time. ${ }^{12-14}$ Also, the incidence of depression is highest at the ages where reproductive value peaks, a pattern characteristic of few diseases.

Defenses are regulated by cues associated with situations in which they are useful; defects are not. ${ }^{15-17}$ The regularity of the relationship between loss and negative affect and the proportionality of low mood to the magnitude of a loss ${ }^{18,19}$ imply that mood is regulated. However, the relationship of depression to events is less consistent. While about $80 \%$ of first episodes in women are preceded by a severe life event, ${ }^{18,20}$ only about one sixth of previously well women develop a depression after a severe life event. ${ }^{21}$ For third and subsequent episodes of endogenous depression, onset is unrelated to life events, ${ }^{22}$ suggesting that many depressive episodes are not defenses.

The global evidence undermines the idea that low mood and depression are defects unrelated to a defense but is insufficient to support any firm conclusion about their adaptive significance. Just as for most other traits, any conclusion about their utility requires consideration of specific hypotheses about how they could have offered a selective advantage.

\section{POSSIBLE FUNCTIONS OF LOW MOOD AND DEPRESSION}

Signaling benefits of several kinds have been attributed to low mood or depression. ${ }^{23}$ An infant's crying motivates its mother to help, an essential mechanism shaped by kin selection. ${ }^{24,25}$ While crying makes a strong link to adult depression, it is less clear that states of passive withdrawal benefit infants. ${ }^{26}$ Lewis ${ }^{27}$ suggested that depression in adults is a plea for help. This view remains prevalent, but the evidence is mixed. The capacity to arouse pity in others may be helpful, but there are few data to support this. However, reactions to patients with chronic depression are mainly negative. ${ }^{28}$ Depression has also been interpreted as a communication designed to manipulate others into providing resources. ${ }^{29,30}$ Following Lewis ${ }^{27}$ and Meyer, ${ }^{31}$ and citing studies of infants, Klerman concluded: "depression is clearly adaptive, especially for infant primates, including man,"32(p135) but, "My current view is that the adult depressive episode represents an attemptat adaptation that has failed,"32(p143) presumably because help was not forthcoming.

Engel and Schmale ${ }^{33,34}$ used the phrase conservation-withdrawal to refer to the presumed utility of the "despair" phase of the behavior pattern of a lost infant monkey. Depression in adults after a loss has been interpreted as analogous to this pattern of infant behavior, and many authors, ${ }^{35}$ including Beck, ${ }^{36}$ emphasize a role for depression in conserving resources. However, unlike hibernation, depression is rarely a state of calm conservation, does not affect all individuals in a group synchronously, and, with the possible 
exception of seasonal depression, ${ }^{37}$ is not usually corrected by the mere passage of time. While conserving energy during bad times is sensible, depression seems poorly designed for this purpose.

Bowlby $^{38}$ emphasized the value of attachment and of aversive feelings when an attachment is threatened or lost. He and his followers have generally treated grief and depression in adults as an epiphenomenon of attachment. ${ }^{39}$ However, it remains to be determined whether grief is merely a design constraint or an adaptation in its own right. ${ }^{40}$

Price and others ${ }^{41,42}$ have suggested the utility of depression as a yielding signal in hierarchy conflicts. Basing their theory on animal models, they recognized that many of their patients with depression were unwilling to yield to a more powerful adversary. If they did finally yield, this signaled to the dominant figure that the person was no longer a threat, ended the conflict, and resolved the depression. ${ }^{43}$ This theory suggests a possible role for high as well as low mood in negotiating hierarchies ${ }^{44}$ and is supported by clinical evidence of episodes of depression precipitated by social competition and resolved by reconciliation. ${ }^{20,45}$ Hartung ${ }^{46}$ has suggested a variation in which selfdeception about one's abilities ("deceiving down") lulls superiors into thinking one is no threat.

Clinicians have long noted that depression is common in people who are pursuing unreachable goals. ${ }^{47,48}$ "Failure to yield" may be an example, in the status competition domain, of this more general situation. When current life plans are not working, the distress and lack of motivation that characterize depression may motivate planning and reassessment $^{49}$ or escape, even by suicide. ${ }^{50}$ Hamburg summarized possible functions of depression, saying,

[when] the subject estimates the probability of effective action is low ... the depressive responses can be viewed as adaptive. ... . Feelings of sadness and discouragement may be a useful stimulus to consider ways of changing [the] situation. ... Moreover, [the] state of sadness may elicit heightened interest and sympathetic consideration on the part of significant other people..$^{51(\mathrm{p} 240)}$
The helplessness literature takes a related view but emphasizes the frequency and costs of incorrect perceptions of lack of control instead of the benefits of a passive strategy. ${ }^{52-54}$ Tiger $^{55}$ offers an explicitly evolutionary view of optimism.

The role of depression in disengaging motivation from an unreachable goal was specified more explicitly in the incentive-disengagement theory of Klinger. ${ }^{56,57}$ If a commitment to pursue a goal encounters an obstacle, efforts increase and become aggressive. If the obstacle cannot be overcome, low mood helps to disengage the commitment and end the cycle. If the individual cannot disengage, low mood escalates. Klinger concludes, "depression is ordinarily, therefore, a normal, adaptive part of disengaging oneself from an incentive." ${ }^{\text {6(p21) }}$ Many other researchers also see a close relationship between depression and difficulty in disengaging from major commitments. ${ }^{58,59}$

This position has been elaborated in the framework of control theory, which suggests that low mood motivates consideration of alternative strategies when the distance from the goal is being reduced more slowly than anticipated. ${ }^{60-62}$ Several related theories have led to evidence that low mood is aroused by a mismatch between achievements and expectations. ${ }^{45,63-65}$ Closely related is work on the information functions of mood. ${ }^{64}$ Low mood shifts cognition to the more systematic ${ }^{66}$ and perhaps the more realistic. ${ }^{67,68}$ Many studies support the relationship of goal pursuit to low mood, ${ }^{69}$ but few have addressed clinical depression.

My previous attempts to explain mood have emphasized the benefits of regulating investment strategies as a function of changes in anticipated levels of payoffs. ${ }^{70-72}$ In a propitious situation, organisms gain by upregulating effort and risk taking. In an unpropitious situation, downregulation of effort and risk taking is adaptive. Mood thus regulates the allocation of effort and resources - toward enterprises, strategies, and times likely to give a high payoff and away from unprofitable enterprises and times when efforts will likely be wasted or dangerous. As Wender and Klein put it,
. . biologically based self-esteemand mood in general-seems to us to have evolutionary utility... If one is subject to a series of defeats, it pays to adopt a conservative game plan of sitting back and waiting and letting others take the risks. Such waiting would be fostered by a pessimistic outlook. Similarly if one is raking in the chips of life, it pays to adopt an expansive risk taking approach, and thus maximize access to scarce resources. ${ }^{73(\mathrm{p} 204)}$

\section{IN WHAT SITUATIONS IS LOW MOOD USEFUL?}

Most attempts to explain low mood have been formulated in terms of specific functions, especially communication, motivation, and regulation of effort. However, a single emotional state may serve several different functions, and different emotions have functions in common. Emotions differ from one another not because they have different functions, but because they were shaped to cope with different situations..$^{64,70,74-78}$ After all, the global function of an emotion or affect is to create a special state in an organism that allows it to cope effectively with the adaptive challenges characteristic of some situation that has recurred and influenced fitness over the course of many generations. Thus, the crucial question about low mood is not its function but in what situations its various characteristics offers fitness advantages.

The characteristics of low mood and the situations that arouse it offer clues to when and how it has been useful. Decreased motivation and activity would obviously be useful mainly in situations in which action would be futile or dangerous. Organisms carefully regulate when and where they exert effort; foraging theory offers robust predictions for one such kind of effort. ${ }^{79,80}$ As the food in a patch is depleted, organisms give up on that patch at close to the optimal time, namely, when the rate of return in the current patch declines below the average rate of return over all patches. If the overall rate of return from all patches drops below the cost, foraging stops. When the snow is deep and the temperature is low, foraging may cost a deer more energy per hour than it 
can gain, so its best option, even if it is starving, is to stand still and wait. ${ }^{35}$

Human behavior is far more complex and is organized around the pursuit of personal goals. In recent years, psychologists have increasingly viewed emotions as arising from an individual's appraisal of how an event will influence goal attainment. ${ }^{75,81,82}$ An enormous body of literature now describes the role of affect in regulating goal pursuit, ${ }^{65,66,83-85}$ but little of this work has made its way into psychiatry and even less is grounded in evolutionary biology. Specific emotions have been matched to particular situations, ${ }^{6}$ and control theorists have documented how emotions are influenced by success or failure in the pursuit of goals. ${ }^{69}$ Situations that regularly arise in the pursuit of goals arouse special states ("mind sets") to deal with them effectively. ${ }^{86}$ Failing to reach a goal is an especially potent elicitor of negative affect. ${ }^{56,59}$ There is considerable agreement that low mood helps to disengage individuals from unproductive efforts.

\section{ARE THE CORE ASPECTS OF DEPRESSION EVER USEFUL?}

It is easy to see how lack of motivation for one activity could free effort for something more productive, but depression is characterized by a more pervasive pessimism, low self-esteem, and reduced initiative. These characteristics pose the core conundrum of depression. They are the exact opposite of the optimism, energy, and a willingness to make changes that would help a person get out of a bad situation. However, there are situations in which active efforts just make things worse. One, well described by Price, ${ }^{41}$ is when challenging a dominant figure starts fights that cannot be won. In this situation, it is far better to inhibit striving and signal submission and a wish for reconciliation. ${ }^{87}$ Another situation is the failure of a major life enterprise. The pursuit of large goals requires constructing expensive social enterprises that are difficult to replace-marriages, friendships, careers, reputation, status, and group memberships. Major setbacks in these enterprises precipitate life crises. In such situations, it is often useful to inhibit any tendency to shift quickly to a different endeavor. The start-up costs for a new enterprise are huge, there is often no certainty that another enterprise can be found at all, and the attractiveness of alternatives may be illusory. Hastily giving up on an unsatisfying marriage or job often takes a person out of the frying pan and into the fire. In this situation, pessimism, lack of energy, low self-esteem, lack of initiative, and fearfulness can prevent calamity even while they perpetuate misery. There are also many other kinds of unpropitious situations, such as lacking a viable life plan or some crucial resource or being so stressed that striving would cause bodily damage. Just as anxiety inhibits dangerous actions, depression inhibits futile efforts.

This seems to contradict the idea that depression facilitates disengagement from unreachable incentives. Which is it? Does depression foster giving up and moving on when efforts to reach a goal are not working, or does it motivate persisting despite little likelihood of success? This apparent contradiction arises from trying to frame the explanation in terms of one function. When depression is instead seen as a state shaped to cope with unpropitious situations, it is clear how it could be useful, both to decrease investment in the current unsatisfying life enterprise and also to prevent the premature pursuit of alternatives. Failure to disengage can cause depression, and depression can make it harder to disengage. This may explain why the low-mood system is so prone to getting stuck in positive feedback loops. ${ }^{8-91}$ Mood dysregulation may now be so prevalent because we are bereft of kin, beliefs, and rituals that routinely extracted our ancestors from such cycles. ${ }^{92}$ Also, the costs of low mood may be small compared with those of inappropriate high mood, so in certain situations the "smoke detector principle" biases the system toward low mood. ${ }^{1}$

Usually, the dilemma is resolved by changing or accepting the current situation or by moving on. When it is not, serious pathology may arise. The argument in this article has so far been presented in the cold quasieconomic terms of behavioral ecology. However, for most people the resources at issue are relationships that are mediated not by calculated reciprocity, but by powerful emotional commitments. To break such commitments and turn energies elsewhere is far different from just moving to a different foraging patch. At least as important as the risks and costs of making a change is the threat to the person's identity, reputation, and sense of a secure place in a social network and the cosmos. As a result, most people do not treat others as objects, to be exploited optimally and then replaced when convenient. Instead, despite the difficulties, they persist in their relationships, for better and for worse. Ambivalent relationships can cause vast suffering. ${ }^{93}$

\section{TESTS}

The several theses presented herein require different kinds of assessment. ${ }^{94,95}$ The first, that it is important to determine if depression is a defense, a dysregulated defense, or a defect, extends a well-recognized distinction from the rest of medicine to psychiatry. The second, that evolutionary hypotheses about low mood and depression are better formulated in terms of the situations that shaped them instead of just their functions either will or will not prove itself useful. The third, that generic low mood and related negative affect have been shaped to deal with unpropitious situations, predicts that the effect of a life event on mood will depend primarily on how it changes the anticipated payoff of future efforts. Many data exist to test this proposal, and initial forays have been made. For instance, depression is precipitated not so much by life events that involve loss, but by those that are humiliating or entrapping. ${ }^{20,96}$ Life events research has moved steadily from lists of events to examination of the individual context of the event. ${ }^{19} \mathrm{~A}$ further step in this direction is to assess an individual's major life goals and ability to achieve them. This requires the ideographic study of why an individual is committed to certain goals 
and that individual's values, relationships, enterprises, strategies, obstacles, anticipated success or failure, strategic conflicts and trade-offs, and decisions about what to do next in life. $^{84}$

A related thesis, that natural selection has partially differentiated several negative affects to deal with different kinds of unpropitious situations, predicts substantial overlap for the characteristics of low mood, depression, anxiety, guilt, and grief. Likewise, the brain mechanisms that mediate them should be tightly intertwined parts of the behavioral inhibition system. ${ }^{97}$ Drugs that relieve depression should (and do) also relieve anxiety. Substantial comorbidity of depression and anxiety disorders $^{98}$ is expected, not only because related brain mechanisms give shared diatheses, but also because situations that involve persistence in futile efforts also involve risk and loss. Much work remains to consider how subtypes of negative affects may match certain situations, such as seasonal low mood in cold, dark seasons and grief after a loss.

The simplest untested prediction is that depression should be common in people who are unable to disengage from unreachable goals. Graduate students who are failing and faculty who are unlikely to make tenure are obvious candidates for study, but other situations are far more common: unrequited love, inability to get work, pursuing an elusive large life goal, or trying to lose weight, stop using drugs, satisfy a fetish, be morally exemplary, get famous, or please a critical parent. Ability to repress such wishes should prevent depression.

Negative thinking and lack of motivation should be especially common in situations characterized by temptation to challenge a dominant figure, failure of a major life enterprise, or lack of a viable life plan. They should be less common after discrete losses, even large ones. Low self-esteem should be an especially prominent part of those depressions that arise from inability to yield in a status competition. Furthermore, if negative thinking functions partly to keep people from prematurely leaving bad situations, then antidepressant treatment should in- crease the proportion of people who leave. It would be interesting to see if drug treatment of spouses who are abused and have depression makes them more likely to leave or to tolerate a bad situation. The benefits of cognitive therapy should be mediated not just by correcting negative distortions, but more specifically by increasing the person's expectations of the effectiveness of future actions.

This perspective also suggests animal and neural models. If the brain mechanisms that regulate foraging are related to those that mediate depression, then antidepressants should change the duration of foraging time in a depleted patch and the willingness to exert effort even when the net rate of return is negative. They might also change preferences for working hard for a large intermittent reward vs easily getting small, frequent rewards. If low mood is an active coordinated state, then the brain mechanisms that mediate it can be blocked at different points, so antidepressants should be effective via multiple mechanisms.

This perspective predicts that depression should be frequent in people who are anxious, dutybound, ambitious, or lacking alternatives because such individuals are especially likely to get themselves into situations in which they are unable to give up a major goal. ${ }^{99}$ People who lack the resources or power to accomplish their goals may be especially vulnerable. ${ }^{100}$ Subjective wellbeing should be (and is) lower in those pursuing large longer-term projects, ${ }^{101,102}$ especially conflicting ones. ${ }^{103}$ It is interesting, in this context, to note that some of the genetic predisposition to depression is mediated by differential exposure to severe life events. ${ }^{104,105}$

Finally, this perspective predicts that social factors should influence rates of depression. Depression should be more common in cultures with rigid hierarchies and in those in which life enterprises tend to be huge, vulnerable, and irreplaceable. Media exposure should increase depression, not just by fostering negative social comparisons, but also by motivating the pursuit of unreachable goals. Relevant here are cross-cultural data that find sub- jective well-being to be higher in societies with greater income equality $^{106}$ and data showing increasing rates of depression in developed societies. ${ }^{107}$

\section{CONCLUSIONS}

Is depression an adaptation? At present, we do not have the evidence needed to say for sure. However, it seems likely that low mood and related negative affects were shaped to help organisms cope with unpropitious situations. Some negative and passive aspects of depression may be useful because they inhibit dangerous or wasteful actions in situations characterized by committed pursuit of an unreachable goal, temptations to challenge authority, insufficient internal reserves to allow action without damage, or lack of a viable life strategy. However, it is essential to emphasize that many depressions are clearly disease states: some caused by dysregulations of negative affect and others by brain defects unrelated to low mood. The fact that low mood, and perhaps some depression, may be useful should not distract attention from recognition that depression is one of humanity's most serious medial problems. ${ }^{108}$ A deeper understanding of the adaptive significance of low mood and depression will improve our ability to prevent and relieve both mood disorders and low moods that are normal, but unnecessary.

Accepted for publication September 28, 1999.

Preparation of this article was made possible by a grant from the Kaplan Foundation, Englewood, NJ, and by support from the Department of Psychiatry and the Institute for Social Research, University of Michigan, Ann Arbor.

I thank Linda Brakel, MD, Deborah Carr, PhD, Helena Cronin, PhD, Allan Gibbard, PhD, Paul Gilbert, PhD, Ursula Goodenough, PhD, John Greden, MD, Annette Hollander, PhD, Gordon Kane, PhD, Lois Kane, Matthew Keller, BA, Kevin Kerber, MD, Timothy Ketelaar, PhD, Raymond Kloss, MD, Richard Lempert, PhD, David Lyons, MD, Jacquelyn Murphy, PhD, Margaret Nesse, MS,

$\overline{\text { ARCH GEN PSYCHIATRY/VOL 57, JAN } 2000 \text { WWW.ARCHGENPSYCHIATRY.COM }}$ 
Daphna Oyserman, PhD, Richard Price, PhD, Peter Railton, PhD, Barbara Smuts, PhD, Charles Webster, $\mathrm{PhD}$, Brant Wenegrat, MD, and Elizabeth Young, MD, for comments on the ideas presented and on early drafts of this article. Corresponding author: Randolph M. Nesse, MD, Institute for Social Research, University of Michigan, Room 5057 426 Thompson St, Ann Arbor, MI 48106-1248 (e-mail:nesse@umich.edu).

\section{REFERENCES}

1. Williams GW, Nesse RM. The dawn of Darwinian medicine. Q Rev Biol. 1991;66:1-22.

2. Nesse RM, Williams GC. Why We Get Sick: The New Science of Darwinian Medicine. New York, NY: Vintage Books; 1994

3. DuPont HL, Hornick RB. Adverse effect of lomotil therapy in shigellosis. JAMA. 1973;226: 1525-1528

4. McGuire MT, Troisi A, Raleigh MM. Depression in evolutionary context. In: Baron-Cohen S, ed. The Maladapted Mind. Hillsdale, NJ: Lawrence A Erlbaum Associates; 1997:255-282.

5. Akiskal HS, McKinney WT Jr. Depressive disorders: toward a unified hypothesis. Science. 1973; 182:20-29.

6. Shaver P, Schwartz J, Kirson D, O'Connor C. Emotion knowledge: further exploration of a prototype approach. J Pers Soc Psychol. 1987;52: 1061-1086.

7. Watson D, Clark LA. Affects separable and inseparable: on the hierarchical arrangement of the negative affects. J Pers Soc Psychol. 1992;62: 489-505.

8. Kessler RC, McGonagle KA, Swartz M, Blazer DG, Nelson CB. Sex and depression in the National Comorbidity Survey, I: lifetime prevalence, chronicity and recurrence. J Affect Disord. 1993;29: 85-96.

9. Olfson M, Broadhead WE, Weissman MM, Leon AC, Farber L, Hoven C, Kathol R. Subthreshold psychiatric symptoms in a primary care group practice. Arch Gen Psychiatry. 1996;53:880886.

10. Judd LL, Akiskal HS, Paulus MP. The role and clinical significance of subsyndromal depressive symptoms (SSD) in unipolar major depressive disorder. J Affect Disord. 1997;45:5-17.

11. Kendler KS, Gardner CO Jr. Boundaries of major depression: an evaluation of DSM-IV criteria. Am J Psychiatry. 1998;155:172-177.

12. Whybrow PC, Akiskal HS, McKinney WT. Mood Disorders: Toward a New Psychobiology. New York, NY: Plenum Publishing Corp; 1984.

13. Akiskal HS, Judd LL, Gillin JC, Lemmi H. Subthreshold depressions: clinical and polysomnographic validation of dysthymic, residual and masked forms. J Affect Disord. 1997;45:53-63.

14. Angst J, Merikangas KR, Presig M. Subthreshold syndromes of depression and anxiety in the community. J Clin Psychiatry. 1997:58:6-10.

15. Janzen DH. Evolutionary physiology of personal defense. In: Townsend CR, Calow $P$, eds. Physiological Ecology: An Evolutionary Approach to Resource Use. Cambridge, Mass: Blackwell Publishers; 1981:145-164.

16. Vander A, Sherman JH, Luciano DS. Human Physiology: The Mechanisms of Body Function. 5th ed. New York, NY: McGraw-Hill Book Co; 1985.
17. Mrosovsky N. Rheostatis. New York, NY: Oxford University Press; 1990.

18. Brown GW, Harris T. Social Origins of Depression. New York, NY: The Free Press; 1978.

19. Monroe SM, Simons AD. Diathesis-stress theories in the context of life stress research: implications for the depressive disorders. Psychol Bull. 1991;110:406-425.

20. Brown GW, Harris TO, Hepworth C. Loss, humiliation and entrapment among women developing depression: a patient and non-patient comparison. Psychol Med. 1995;25:7-21.

21. Monroe SM, Simons AD, Thase ME. Onset of depression and time to treatment entry: roles of life stress. J Consult Clin Psychol. 1991;59:566-573.

22. Frank E, Anderson B, Reynolds CF III, Ritenour A, Kupfer DJ. Life events and the research diagnostic criteria endogenous subtype: a confirmation of the distinction using the Bedford College methods. Arch Gen Psychiatry. 1994;51:519524.

23. Johnson-Laird PN, Oatley K. The language of emotions: an analysis of a semantic field. Cogn Emotion. 1989;3:81-123.

24. Barr RG. The early crying paradox: a modest proposal. Hum Nature. 1990;1:355-389.

25. Lummaa V, Vuorisalo T, Barr RG, Lehtonen L. Why cry? adaptive significance of intensive crying in human infants. Evolution Hum Behav. 1998; 19:193-202.

26. Rosenblum LA, Plimpton EH. The infant's effort to cope with separation. In: Lewis M, Rosenblum LA, eds. The Uncommon Child. New York, NY: Plenum Publishing Corp; 1981:225-257.

27. Lewis AJ. Melancholia: a clinical survey of depressive states. J Mental Sci. 1934;80:1-43.

28. Coyne JC, Kessler RC, Tal M, Turnbull J. Living with a depressed person. J Consult Clin Psychol. 1987;55:347-352.

29. Hagen $\mathrm{EH}$. The functions of postpartum depression. Evolution Hum Behav. In press.

30. Watson PW, Andrews PW. An evolutionary theory of unipolar depression as an adaptation for overcoming constraints of the social niche. Presented at: Annual Meeting of the Human Behavior and Evolution Society; July 10, 1998; Davis, Calif.

31. Lief A, ed. The Common Sense Psychiatry of Dr Adolf Meyer. New York, NY: McGraw Hill Book Co; 1948.

32. Klerman GL. Depression and adaptation. In: Friedman RJ, Katz MM, eds. The Psychology of Depression. Washington DC: VH Winston \& Sons; 1974:127-156.

33. Engel G, Schmale A. Conservation-withdrawal: a primary regulatory process for organismic homeostasis. In: Porter R, Night J, eds. Physiology, Emotion, and Psychosomatic IIIness. Amsterdam, the Netherlands: Associated Scientific Publishers; 1972:57-85.

34. Schmale A, Engel GL. The role of conservationwithdrawal in depressive reactions. In: Benedek T, Anthony EJ, eds. Depression and Human Existence. Boston, Mass: Little Brown \& Co; 1975: 183-198.

35. Thierry B, Steru L, Chermat R, Simon P. Searching-waiting strategy: a candidate for an evolutionary model of depression? Behav Neural Biol. 1984:41:180-189

36. Beck AT. Depression as an evolutionary strategy. Presented at: Annual Meeting of the Human Behavior and Evolution Society; June 27, 1996; Evanston, III.

37. Rosenthal NE, Sack DA, Gillin JC, Lewy AJ, Goodwin FK, Davenport Y, Mueller PS, Newsome DA, Wehr TA. Seasonal affective disorder: a descrip- tion of the syndrome and preliminary findings with light therapy. Arch Gen Psychiatry. 1984; 41:72-80.

38. Bowlby J. Attachment and Loss. New York, NY: Basic Books Inc Publishers; 1969.

39. Archer J. The Nature of Grief. New York, NY: OXford University Press; 1999.

40. Nesse RM. Is grief really maladaptive? Evolution Hum Behav. In press.

41. Price JS. The dominance hierarchy and the evoIution of mental illness. Lancet. 1967;2:243246.

42. Price J, Sloman L, Gardner R Jr, Gilbert P, Rohde $P$. The social competition hypothesis of depression. Br J Psychiatry. 1994;164:309-315.

43. Sloman L, Price J, Gilbert P, Gardner R. Adaptive function of depression: psychotherapeutic implications. Am J Psychother. 1994:48:401-416.

44. Gardner R Jr. Mechanisms in manic-depressive disorder: an evolutionary model. Arch Gen Psychiatry. 1982;39:1436-1441.

45. Gilbert P. Depression: The Evolution of Powerlessness. New York, NY: Guilford Publications; 1992.

46. Hartung J. Deceiving down. In: Lockard JS, Paulhus D, eds. Self-deception: An Adaptive Mechanism? Englewood Cliffs, NJ: Prentice-Hall International Inc; 1988:170-185.

47. Bibring E. The mechanisms of depression. In: Greenacre P, ed. Affective Disorders. New York, NY: International Universities Press; 1953:1348.

48. Davis DR. Depression as adaptation to crisis. $\mathrm{Br}$ J Med Psychol. 1970;43:109-116.

49. Gut E. Productive and Unproductive Depres sion. New York, NY: Basic Books Inc Publishers; 1989.

50. Baumeister RF. Suicide as escape from self. Psychol Rev. 1990;97:90-113.

51. Hamburg DA. Coping behavior in life-threatening circumstances. Psychother Psychosom. 1974;23: 13-25.

52. Seligman MEP. Helplessness: On Depression, Development, and Death. San Francisco, Calif: WH Freeman \& Co; 1975

53. Wortman CB, Brehm JW. Responses to uncontrollable outcomes: an integration of reactance theory and the learned helplessness model. In: Berkowitz L, ed. Advances in Experimental Social Psychology. New York, NY: Academic Press Inc; 1975:277-336.

54. Peterson C, Maier SF, Seligman ME. Learned Helplessness. New York, NY: Oxford University Press; 1993.

55. Tiger L. Optimism: The Biology of Hope. New York, NY: Simon \& Schuster; 1979.

56. Klinger $\mathrm{E}$. Consequences of commitment to and disengagement from incentives. Psychol Rev. 1975;82:1-25.

57. Klinger E. Meaning and Void: Inner Experience and the Incentives in People's Lives. Minneapolis: University of Minnesota Press; 1977.

58. Janoff-Bulman R, Brickman P. Expectations and what people learn from failure. In: Feather NT, ed. Expectations and Action. Hillsdale, NJ: Lawrence A Erlbaum Associates; 1982.

59. Brickman P. Commitment, Conflict, and Caring. Englewood Cliffs, NJ: Prentice-Hall International Inc; 1987

60. Carver CS, Scheier MF. Attention and Selfregulation: A Control Theory Approach to Human Behavior. New York, NY: SpringerVerlag; 1983.

61. Hyland ME. Control theory interpretation of psychological mechanisms of depression: compari- 
son and integration of several theories. Psychol Bull. 1987;102:109-121.

62. Carver CS, Scheier MF. Origins and functions of positive and negative affect: a control-process view. Psychol Rev. 1990;97:19-35.

63. Higgins ET. Self-discrepacy: a theory relating self and affect. Psychol Rev. 1987;94:319-340.

64. Schwartz N. Feelings as information: informational and motivational functions of affective states. In: Higgins ET, Sorrentino R, eds. Handbook of Motivation and Cognition. New York, NY: Guilford Press; 1990:527-559.

65. Brunstein JC. Personal goals and subjective wellbeing. J Pers Soc Psychol. 1993;65:10611070.

66. Schwartz N, Clore GL. Feelings and phenomenal experiences. In: Higgens ET, Kruglanski AW, eds. Social Psychology: Handbook of Basic Principles. New York, NY: Guilford Publications; 1996: 433-465.

67. Alloy LB, Abramson L. Depressive realism: four theoretical perspectives. In: Alloy L, ed. Cognitive Processes in Depression. New York, NY: Guilford Press; 1988.

68. Taylor SE, Brown JD. Illusion and well-being: a social psychological perspective on mental health. Psychol Bull. 1988;103:193-210.

69. Martin LL, Tesser A, eds. Striving and Feeling: Interactions Among Goals, Affect, and Selfregulation. Hillsdale, NJ: Lawrence A Erlbaum Associates; 1996.

70. Nesse RM. Evolutionary explanations of emotions. Hum Nature. 1990;1:261-289.

71. Nesse RM. What is mood for? Psycholoquy [journal online]. 1991;2:9.2. Available at: ftp:// ftp.princeton.edu/pub/harnad/Psycholoquy /1991.volume.2/psyc.91.mood.1.nesse. Accessed October 19, 1999.

72. Nesse RM. What good is feeling bad? The Sciences. November/December 1991:30-37.

73. Wender PH, Klein DF. Mind, Mood and Medicine. New York, NY: New American Library; 1982.

74. Tooby J, Cosmides L. The past explains the present: emotional adaptations and the structure of ancestral environments. Ethol Sociobiol. 1990; 11:375-424.

75. Oatley K, Jenkins JM. Human emotions: function and dysfunction. Annu Rev Psychol. 1992:43:5585.

76. Ekman P, Davidson RJ, eds. The Nature of Emotion: Fundamental Questions. New York, NY: OXford University Press; 1994:97-143.

77. Frijda NH. Varieties of affect: emotions and epi- sodes, moods and sentiments. In: Ekman P, Davidson RJ, eds. The Nature of Emotion: Fundamental Questions. New York, NY: Oxford University Press; 1994:59-67.

78. Nesse RM, Berridge KC. Psychoactive drug use in evolutionary perspective. Science. 1997;278: 63-66.

79. Charnov EL. Optimal foraging: the marginal value theorem. Theor Popul Biol. 1976:9:129-136.

80. Stephens DW, Krebs JR. Foraging theory. In: Krebs JR, Clutton-Brock T, eds. Monographs in Behavior and Ecology. Princeton, NJ: Princeton University Press; 1986

81. Ellsworth P. Some implications for cognitive appraisal theories of emotion. Int Rev Stud Emotion. 1991;1:143-161.

82. Lazarus RS. Emotion and Adaptation. New York, NY: Oxford University Press; 1991

83. Cantor N. From thought to behavior: "having" and "doing" in the study of personality and cognition. Am Psychol. 1990;45:735-750.

84. Diener E, Fujita F. Resources, personal strivings, and subjective well-being: a nomothetic ideographic approach. J Pers Soc Psychol. 1995; 68:926-935.

85. Fleeson W, Cantor N. Goal relevance and the affective experience of daily life: ruling out situational explanations. Motivation Emotion. 1995; 19:25-57.

86. Gollwitzer PM. Action phases and mind-sets. In: Higgins ET, Sorrentine RM, eds. Handbook of Motivation and Cognition. New York, NY: Guilford Press; 1990:53-92.

87. de Waal FB. Peacemaking Among Primates. Cambridge, Mass: Harvard University Press; 1989.

88. Beck AT. Depression: Clinical, Experimental, and Theoretical Aspects. New York, NY: Hoeber Medical Division; 1967

89. Teasdale JD. Negative thinking in depression: cause, effect, or reciprocal relationship? Adv Behav Res Ther. 1983;5:3-25.

90. Pyszczynski T, Greenberg J. Self-regulatory perseveration and the depressive self-focusing style: a self-awareness theory of reactive depression. Psychol Bull. 1987;102:122-138.

91. Nolen-Hoeksema S, Morrow J. Effects of rumination and distraction on naturally occurring depressed mood. Cogn Emotion. 1993;7:561570.

92. Seligman ME. Learned Optimism. New York, NY: Random House Inc; 1991.

93. Vaillant GE. Adaptation to Life. Boston, Mass: Little Brown \& Co; 1977
94. Nesse RM. Testing evolutionary hypotheses about mental disorders. In: Stearns S, ed. EvoIution in Health and Disease. New York, NY: OXford University Press; 1999:260-266.

95. Nesse RM, Williams GC. Research designs that address evolutionary questions about medical disorders. In: Stearns S, ed. Evolution in Health and Disease. New York, NY: Oxford University Press; 1999:16-26.

96. Gilbert P, Allan S. The role of defeat and entrapment (arrested flight) in depression: an exploration of an evolutionary view. Psychol Med. 1998;28:585-598.

97. Gray JA. Fear and Stress. 2nd ed. Cambridge, England: Cambridge University Press; 1987.

98. Maser J, Cloninger R. Comorbidity of Mood and Anxiety Disorders. Washington, DC: American Psychiatric Press; 1990.

99. Little BR, Lecci L, Watkinson B. Personality and personal projects: linking big five and PAC units of analysis. J Pers. 1992;60:501-525

100. Wenegrat B. IIIness and Power. New York: New York University Press; 1995

101. Palys TS, Little BR. Perceived life satisfaction and the organization of personal project systems. J Pers Soc Psychol. 1983;44:1221-1230.

102. Emmons RA. Abstract versus concrete goals: personal striving level, physical illness, and psychological well-being. J Pers Soc Psychol. 1992; 62:292-300.

103. Emmons RA, King LA. Conflict among personal strivings: immediate and long-term implications for psychological and physical well-being. J Pers Soc Psychol. 1988;54:1040-1048.

104. Kendler KS, Karkowski-Shuman L. Stressful life events and genetic liability to major depression: genetic control of exposure to the environment? Psychol Med. 1997;27:539-547.

105. Kendler KS. Major depression and the environment: a psychiatric genetic perspective. Pharmacopsychiatry. 1998:31:5-9.

106. Kahnemann D, Deiner E, Schwarz N. WellBeing: Foundations of Hedonic Psychology. New York, NY: Russell Sage Foundation; 1999.

107. Cross-National Collaborative Group. The changing rate of major depression: cross-national comparisons. JAMA. 1992;268:3098-3105

108. Murray CJ, Lopez AD. The Global Burden of Disease: A Comprehensive Assessment of Mortality and Disability From Diseases, Injuries, and Risk Factors in 1990 and Projected to 2020. Cambridge, Mass: Harvard University Press; 1996. 